\title{
Agentes Comunitários de Saúde do município de Mari-PB e suas percepções como educadores em saúde
}

\author{
Francikely da Cunha Bandeira \\ Doutoranda em Educação pela Universidade Federal da Paraíba. Mestre em Educação pela mesma \\ Universidade. \\ kely01kely@hotmail.com \\ Luiz Gonzaga Gonçalves \\ Doutor em Educação pela Universidade Metodista de Piracicaba. Pós doutorado em Educação pela \\ Universidade Federal do Rio Grande do Sul. \\ 凹luggoncalves@uol.com.br
}

\begin{abstract}
Resumo:
Este estudo tem como objetivo verificar a percepção que os Agentes Comunitários de Saúde do município de Mari - PB têm sobre o próprio trabalho. Trata-se de um estudo qualitativo, exploratório, realizado por meio de questionários e grupos focais, com Agentes Comunitários de Saúde do referido município. Os questionários foram aplicados com participação de todos os cinquenta e três Agentes atuantes locais, e os grupos focais foram realizados em dois momentos, com quatro agentes de saúde e depois com sete. Os dados provenientes dos questionários foram organizados, a partir dos quais foi possível traçar um perfil da categoria. Dos dados provenientes dos grupos focais, surgiram três núcleos argumentativos: o Agente Comunitário como transmissor de informações, percepção do desempenho individual das atividades e burocratização da função. Observou-se que os Agentes têm se compreendido como transmissores de informações, algumas vezes "usados" para atender demandas entendidas como alheias à função, o que tem contribuído para que seja gerada certa sobrecarga de atividades. Percebem também que o trabalho tem se tornado mais individual e burocrático uma vez que novas atribuições têm sido agregadas à função dificultando atividades de caráter mais coletivo. A superação destas dificuldades é possível a partir de um olhar mais cuidadoso para a categoria, entendendo que as atribuições dos Agentes devem convergir, sempre e primeiramente, com as necessidades da população local.
\end{abstract}

Palavras-chave: Prática educativa, trabalho, agentes comunitários de saúde, Mari.

\section{Community Health Agents of the municipality of Mari-PB and their perceptions as health educator}

\begin{abstract}
:
This study aims to verify the perception that Community Health Agents of Mari - PB have about their own work. This is a qualitative, exploratory study conducted through questionnaires and focus groups with Community Health Agents of the municipality. The questionnaires were applied with the participation of all fifty-three local agents, and the focus groups were conducted in two moments with four health agents and then with seven. Data from the questionnaires were organized from which it was possible to draw a profile of the category. From the data coming from the focus groups, three argumentative cores emerged: the Community Agent as a transmitter of information, perception of the individual performance of the activities and bureaucratization of the function. It was observed that the Agents have been understood as transmitters of information, sometimes "used" to meet
\end{abstract}


demands understood as outside the function, which has contributed to generate some overload of activities. They also realize that work has become more individual and bureaucratic as new assignments have been added to the function making collective activities get difficult. Overcoming these difficulties is possible from a more careful look at the category, understanding that the Agents' attributions should always and firstly converge with the needs of the local population.

Keywords: Educational practice, work, community health agents, Mari.

\section{Agentes Comunitarios de salud del municipio de Mari-PB y sus percepciones como educadores en salud}

\section{Resumen:}

Este estudio tiene como objetivo verificar la percepción que los Agentes Comunitarios de Salud del municipio de Mari - PB tienen sobre su propio trabajo. Se trata de un estudio cualitativo, exploratorio, realizado por medio de cuestionarios y grupos focales, con Agentes Comunitarios de Salud del referido municipio. Los cuestionarios han sido aplicados con participación de todos los cincuenta y tres Agentes actuantes locales, y los grupos focales han sido realizados en dos momentos, con cuatro agentes de salud y después con siete. Se ha organizado los datos provenientes de los cuestionarios y a partir de ellos ha sido posible trazar un perfil de la categoría. De los datos provenientes de los grupos focales, han surgido tres núcleos argumentativos: el Agente Comunitario como transmisor de informaciones, percepción del desempeño individual de las actividades y burocratización de la función. Se ha observado que los Agentes se ven como transmisores de informaciones, algunas veces "usados" para atender demandas entendidas como ajenas a la función, lo que ha contribuido para que sea generada alguna sobrecarga de actividad. Perciben también que el trabajo se ha hecho más individual y burocrático una vez que nuevas atribuciones han sido agregadas a la función dificultando actividades de carácter más colectivo. La superación de estas dificultades es posible a partir de una mirada más cautelosa hacia la categoría, entendiendo que las atribuciones de los Agentes deben converger, siempre y antes que todo, con las necesidades de la población local.

Palabras clave: Práctica educativa, trabajo, agentes comunitarios de salud, Mari.

\section{INTRODUÇÃO}

Os Agentes Comunitários de Saúde - ACS são trabalhadores que atuam no nível de Atenção Primária à Saúde desde 1991, quando o Programa de Agentes Comunitários de Saúde - PACS foi implantado pelo Ministério da Saúde no âmbito do Sistema Único de Saúde - SUS e em 1994, os Agentes foram integrados ao Programa Saúde da Família, todavia, o Programa existia desde 1988, no Ceará.

Os ACS são fundamentais para o Sistema de Saúde por construírem vínculos entre as populações e os serviços de saúde. O pertencimento ao local de trabalho e a condição de trabalhador não especializado o caracteriza como um trabalhador sui generis.

As atribuições dos ACS são diversas. As atividades típicas da categoria estão sujeitas a mudanças por sofrerem, ajustes relacionados à organização do trabalho, como às necessidades específicas de cada lugar (NOGUEIRA, 2000). Contudo, a partir de uma breve análise documental, é possível verificar que as atribuições conferidas aos Agentes seguem 
duas linhas orientadoras, que são atividades de promoção à saúde e de prevenção de doenças a serem desenvolvidas através de atividades individuais e coletivas (MINAYO, 1990; BRASIL, 2002; BRASIL, 2006; BRASIL, 2012; BRASIL, 2017; BRASIL, 2018). As atividades individuais são aquelas desenvolvidas pelo Agente na sua área de atuação, diretamente com as famílias; já as coletivas correspondem às ações que têm maior abrangência, em momentos de reuniões com grupos da população.

Atualmente, existem no Brasil mais de 280 mil ACS (de acordo com dados do Cadastro Nacional dos Estabelecimentos de Saúde - CNES) atuando diariamente em todo território nacional, cuja cobertura populacional equivale a $63,34 \%$ da população. No Nordeste a cobertura populacional é de $84,56 \%$, na Paraíba, a cobertura é de $97,55 \%$.

No município de Mari - PB onde ACS atuam desde 1994, quando o PACS foi implantado, a cobertura chegou a $100 \%$ da população. Nos mais de vinte anos, os ACS têm assumido diferentes atribuições. Nos primeiros anos do Programa, atividades de caráter coletivo eram mais frequentes e posteriormente outras atividades foram, aos poucos, sendo incorporadas e priorizadas. Neste sentido, o objetivo deste trabalho é compreender como os Agentes Comunitários de Saúde do município de Mari - PB percebem sua prática laboral.

\section{METODOLOGIA/ MATERIAL E MÉTODOS}

Tratou-se de um estudo qualitativo, de finalidade exploratória (MINAYO, 2007) baseado na etnometodologia (COULON, 1995), realizado em 2016, com Agentes Comunitários de Saúde do município de Mari, no Estado da Paraíba. O município fica localizado na mesorregião da mata paraibana e dista $73 \mathrm{~km}$ da capital João Pessoa. De acordo com o Departamento da Atenção Básica do Ministério da Saúde, Mari apresentava 100\% de cobertura considerando a Estratégia Saúde da Família - ESF da qual fazem parte os ACS.

Foram utilizados como instrumentos para coleta de dados: questionários (MARCONI E LAKATOS, 2003) e grupos focais (GATTI, 2005) empregados em dois momentos distintos e complementares. A escolha se justifica pelo interesse, além de compreender a prática educativa da categoria, em traçar seu perfil, o que foi possível com as entrevistas. Adotou-se como critério de exclusão para as entrevistas, o afastamento/falta do ACS no dia da realização 
das entrevistas, bem como a possível negação de participação. Utilizou-se como critério para formação dos grupos focais as diferentes formas de ingresso na função entendendo que estas podem indicar diferenças quanto ao perfil dos trabalhadores devido às exigências de cada uma. Considerando as diferenças quanto às quantidades de ACS resultantes de cada tipo de forma de ingresso, optou-se por considerar como referência o número de Agentes contratados e concursados, que era o mesmo, isto é, quatro, deste modo foram convidados também, quatro Agentes oriundos de processo seletivo. Pelo número de participantes optouse por realizar dois grupos. Adotou-se como critério de exclusão o não comparecimento para a atividade que foi previamente agendada.

Os questionários e os grupos focais foram aplicados/realizados em maio de $2016 \mathrm{em}$ momentos diferentes e complementares. As entrevistas estruturadas foram compostas por 17 questões que buscavam informações que permitissem traçar um perfil do grupo.

Os grupos focais foram realizados em dias subsequentes no mesmo local seguindo um mesmo roteiro previamente elaborado com doze questões orientadoras. O primeiro GF aconteceu com quatro ACS que ingressaram na função por meio de contrato temporário. 0 segundo GF incluiu três ACS que ingressaram por meio de processo seletivo e quatro que ingressaram por meio de concurso público. Quatro pesquisadores acompanharam os grupos. Utilizou-se gravador de áudio para registrar as falas que foram transcritas na íntegra. 0 material foi submetido à leitura exploratória para apropriação do conteúdo e em seguida realizou-se leitura exaustiva para dar maior profundidade à apreensão.

Para análise e interpretação, recorreu-se à hermenêutica dialética (MINAYO, 2007) para explorar definições permitidas pelo texto. Na organização do material buscou-se identificar os núcleos de argumentação mais emergentes a fim de apreender e interpretar aspectos da prática laboral dos Agentes que permitissem alcançar a compreensão que os sujeitos têm do próprio trabalho. O projeto obteve aprovação do Comitê de Ética em Pesquisa da Universidade Federal da Paraíba, expressa por meio do Parecer nํ․ 55976416.3.0000.5188. 


\section{RESULTADOS E DISCUSSÃO}

A atuação dos Agentes Comunitários de Saúde em Mari completou 26 anos em 2016. A maior parte dos que ainda atuavam na função era proveniente de processo seletivo que foi utilizado como exclusivo critério para ingresso na função no local por um período de dez anos, tendo sido posteriormente substituída por concurso público e mais recentemente temse praticado contratos temporários. Identificou-se que a maior parte de Agentes com histórico de participação em atividade comunitária está entre os que fizeram processo seletivo.

Tabela 1 - Histórico dos Agentes Comunitários de Saúde no município de Mari-PB, no período $1994-2016$

\begin{tabular}{|c|c|c|c|}
\hline $\begin{array}{c}\text { ANO DE } \\
\text { INGRESSO }\end{array}$ & $\begin{array}{l}\text { PERMANECEM } \\
\text { NA FUNÇÃO }\end{array}$ & FORMA DE INGRESSO & $\begin{array}{c}\text { QUE TIVERAM } \\
\text { PARTICIPAÇÃO EM } \\
\text { TRABALHO } \\
\text { COMUNITÁRIO }\end{array}$ \\
\hline 1994/PACS & 6 & Processo seletivo & 4 \\
\hline 1998/PACS & 13 & Processo seletivo & 9 \\
\hline 2000/PACS & 15 & Processo seletivo & 4 \\
\hline 2004/PSF & 7 & Processo seletivo & 5 \\
\hline 2010/PSF & 1 & Concurso Público & 0 \\
\hline 2013/PSF & 2 & Contrato temporário & 1 \\
\hline 2014/PSF & 2 & Contrato temporário & 0 \\
\hline 2015/PSF & $6^{*}$ & $\begin{array}{l}\text { Contrato temporário/ } \\
\text { Concurso Público }\end{array}$ & 1 \\
\hline 2016/PSF & 1 & Contrato temporário & 0 \\
\hline
\end{tabular}

\footnotetext{
*5 por concurso público e 1 por contrato temporário

Fonte: Dados da pesquisa. Mari -PB. Elaborado pelos autores
}

Com base nos questionários aplicados com a participação de todos os Agentes Comunitários atuantes em Mari foi possível traçar um perfil da categoria, a partir do qual foi 
possível observar que é composta predominantemente pelo sexo feminino que compõe 73,5\% da categoria. A prevalência etária situa-se entre 34 e 49 anos correspondendo a $62,26 \%$. A maior parte atua na zona urbana, 71,7\%, quanto à forma de ingresso na função predominou o processo seletivo simplificado, com $77,35 \%$ da categoria.

Tabela 2 - Perfil dos Agentes Comunitários de Saúde atuantes em Mari-PB/2016

\begin{tabular}{|c|c|c|c|c|}
\hline Sexo & Idade & Forma de Ingresso & $\begin{array}{l}\text { Área de } \\
\text { atuação }\end{array}$ & Escolarização \\
\hline $\begin{array}{l}\text { Masculino } \\
26,5 \%\end{array}$ & $\begin{array}{c}18 \text { a } 33 \text { anos } \\
22,65 \%\end{array}$ & $\begin{array}{c}\text { Processo seletivo } \\
\text { simplificado } \\
77,35 \%\end{array}$ & $\begin{array}{c}\text { Zona urbana } \\
71,7 \%\end{array}$ & $\begin{array}{c}\text { Ensino } \\
\text { Fundamental } \\
9,42 \%\end{array}$ \\
\hline $\begin{array}{c}\text { Feminino } \\
73,5 \%\end{array}$ & $\begin{array}{c}34 \text { a } 49 \text { anos } \\
62,26 \%\end{array}$ & $\begin{array}{c}\text { Concurso público } \\
9,45 \%\end{array}$ & $\begin{array}{l}\text { Zona rural } \\
28,3 \%\end{array}$ & $\begin{array}{c}\text { Ensino Médio } \\
77,35 \%\end{array}$ \\
\hline- & $\begin{array}{l}\text { Mais de } 50 \\
\text { anos } \\
15,09 \%\end{array}$ & $\begin{array}{c}\text { Contrato temporário } \\
\qquad 13,20 \%\end{array}$ & - & $\begin{array}{l}\text { Ensino Superior* } \\
\qquad 13,20 \%\end{array}$ \\
\hline
\end{tabular}

* Considerou-se ensino superior completo e incompleto.

Fonte: Dados da pesquisa. Mari - PB. Elaborado pelos autores

A partir da exploração do conteúdo do corpus da pesquisa (resultante dos grupos focais) chegou-se a três núcleos argumentativos principais em torno dos quais se organizam as falas: O ACS como transmissor de informações, percepção do desempenho individual das atividades e burocratização da função.

\section{o Agente Comunitário de Saúde como transmissor de informações}

O entendimento do Agente como transmissor de informações emerge nas falas ${ }^{1}$, vinculado à compreensão do trabalho num sentido educativo.

O que é que um professor faz em sala de aula? Ele está justamente passando informação verdadeira e está educando aquela criança, aquele jovem e é justamente o que a gente faz, a gente também precisa passar informações verdadeiras [...] ou seja, eu vou estar educando aquela comunidade. (GF 2)

\footnotetext{
${ }^{1}$ As falas serão identificadas através das indicações GF 1 para grupo focal 1 e GF 2 para grupo focal 2.
} 
A gente educa com a informação, faz que a pessoa mude seu modo de pensar, ver, agir também, e as pessoas também nos educam e nos informam com coisas repassadas numa visita. (GF 2)

Eu me cobro muito para passar para aquelas pessoas a informação certa, não inventar, não mentir e sim levar a informação correta e trabalhar (GF 1)

Além da gente informar, você tem que quebrar paradigmas. A gente está plantando sim alguma coisa e a educação é assim, não é você vai e pronto. Vai mudando aos poucos (GF 2)

Muita gente usa a gente somente como portador de informação: e o dentista e o médico? Aí a gente tem que saber as informações para passar porque se a gente não souber, mais para frente pode ver que a gente vai ouvir reclamação (GF 1)

Prevalece nas falas o entendimento da transmissão de informação como uma prática educativa em saúde, uma vez que se pretende, através dela, uma apropriação por parte da população em relação a determinado tema (BRASIL, 2009). É preciso destacar também que, a ideia de transmissão pressupõe a ideia de recepção, isto é: há do outro lado alguém que tem algum interesse em receber a informação. Assim, se a transmissão de informação é pensada como forma de educação, é possível identificar também certa limitação quanto ao entendimento do que se entende por educação no sentido de não conceber várias formas de educar (BRANDÃO, 1981) e por não demonstrar preocupação sobre a perspectiva dessa prática educativa (NESPOLI, 2017). Há também o reconhecimento de que lidar com o trabalho informativo/educativo é complexo e, às vezes, lento em seus resultados.

Outro sentido dado à informação se expressa na última fala apresentada, quando se refere mais especificamente à questões de funcionamento dos serviços e não propriamente dito à um assunto de saúde. A este respeito observemos os comentários a seguir:

Muita informação que se precisa parte de nós, não é? Escolar, saúde, sempre eles pedem listas" (GF 1).

Qualquer informação, qualquer coisa que tenha para passar para as comunidades são os ACS (GF 2)

Atualmente é tanta sobrecarga que o trabalho do ACS está deixando de lado a parte mais importante que é a promoção e prevenção, que é o lado educativo. (GF 1)

Este sentido refere-se às necessidades diversas que o município tem de realizar, por exemplo, levantamentos de dados, e para isto, recorre-se aos ACS. De acordo com uma das 
afirmações, esta "demanda" gera certa sobrecarga no trabalho dos Agentes, ao agregar atividades "extras" à rotina. A sobrecarga pode ser entendida a partir de duas perspectivas, objetiva e subjetiva, neste caso, é entendida a partir da perspectiva objetiva uma vez que está marcado pelo impacto da acumulação de tarefas (CARDOSO; GALERA; VIEIRA, 2012).

\section{Percepção do desempenho individual das atividades}

As atribuições dos ACS são descritas através de atividades individuais e coletivas, o que pode ser observado, além de outros documentos, nas Políticas Nacionais da Atenção Básica, documentos que tratam das atribuições de cada categoria profissional desse nível de atenção (BRASIL, 2017). Neste sentido, quando perguntados sobre o que é considerado como mais importante no trabalho dos ACS, declararam:

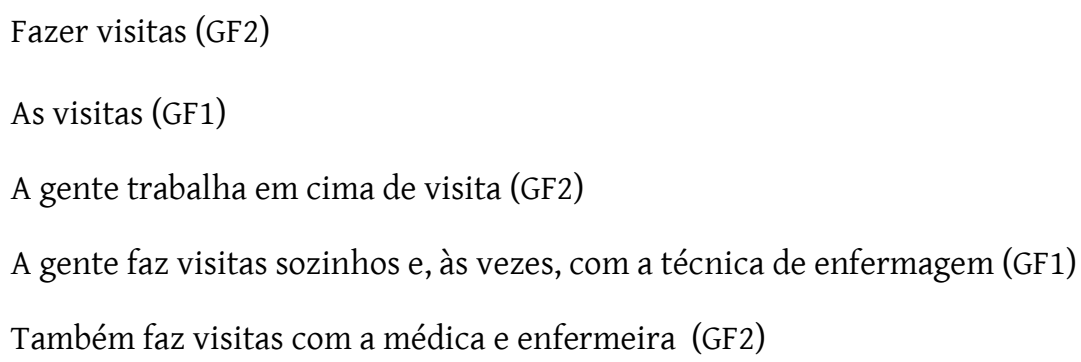

As afirmativas dos primeiros a se pronunciarem foram confirmadas pelos demais, de modo que algumas respostas se repetiram como as três primeiras, por exemplo. Não houve resposta discordante quanto à pergunta, o que concedeu às visitas domiciliares estatuto de atividade mais importante para os Agentes.

A visita domiciliar constitui um importante instrumento de trabalho dos Agentes através do qual realizam cadastramentos e acompanhamentos familiares (BRASIL, 2000). De acordo com as falas, o instrumento tem sido privilegiado e embora sua importância seja inquestionável, sabe-se que deve ser utilizado com outros instrumentos que permitam momentos de atividades coletivas (BRASIL, 2001). Entende-se que a ênfase dada a esta atividade individual tende a comprometer outras potencialidades do trabalho do ACS por promover uma ação fragmentada que dificulta a perspectiva da integralidade das ações (BORSTEIN, 2017). 
Diversos documentos, como as Políticas Nacionais de Atenção Básica, documentos de avaliação tais como vemos em Minayo (1991), Brasil (2000), Brasil (2006) e Brasil (2018), entre vários outros, esclarecem que as atividades dos Agentes seguem em dois sentidos: individuais e coletivas (BRASIL, 2012). Neste sentido, afirmaram:

Antes, todos os meses, todos, a gente se reunia numa igreja, numa associação de moradores com grupos de gestantes, com hipertensos, com diabéticos só para fazer palestras (GF2).

Eram reuniões rápidas de trinta minutos e ouvia, tirava as dúvidas das mulheres porque às vezes quando é um médico elas não têm tanta abertura para falar e com a gente, como elas conhecem, elas falam sobre tudo [...] Então assim... A parte educativa é muito difícil e requer muito tempo, tem que ter tempo e é isso que a gente hoje não tem. (GF2)

É. Tinha reuniões que era só nós. Nós mesmos fazíamos, organizávamos, por exemplo, sobre aleitamento materno, então a gente fazia cartaz, falava da importância do aleitamento materno. (GF2)

Chama atenção o fato de que as afirmações acima resultaram do grupo focal 2, constituído por Agentes que ingressaram por processo seletivo, ou seja, que estão há mais tempo na função indicando que houve um momento em que se dava mais atenção a esse tipo de atividade.

A percepção da maior importância da visita domiciliar em detrimento de práticas coletivas contribui significativamente para a individualização das atividades dos Agentes e limita o alcance dos resultados por vários motivos, dentre eles: menor possibilidade de enriquecimento do diálogo assim como do compartilhamento de experiências e das discussões, as orientações tem baixo alcance e menor possibilidade de serem ampliadas e a fragilização da coletividade da categoria (VASCONCELOS, 1981).

\section{Burocratização da função}

Este núcleo de problemas emergiu como consequência do anterior, quando os Agentes foram questionados sobre os motivos que têm contribuído para a prevalência da visita domiciliar na rotina de trabalho. As respostas foram: 
Foi depois do E-SUS ${ }^{2}$, no caso. (GF 2)

Burocracia! (GF 2)

É! E agora atribui mais uma função ao ACS, que é digitador (GF 2)

Depois do E-SUS, nós nos vemos, quando não estamos na área, só para quando é para digitar, que é o tempo que a gente tem. (GF 2)

Porque, na verdade, tem que alcançar meta, alcançar meta. Quando tem muitas atribuições, às vezes, quero um levantamento disso, um levantamento daquilo, quer dizer, o processo educativo está ficando para trás. (GF 2)

A referência a outras diferentes atribuições conforme já indicado anteriormente reafirma a percepção de sobrecarga de atividades dos Agentes. O E-SUS citado na primeira fala é o atual Sistema de registro de informações da Atenção Básica. Os dados obtidos pelos Agentes são mensalmente organizados para alimentar sistema, atribuição que foi acrescida à rotina dos trabalhadores, é por isto que na terceira fala emerge a identificação também como digitador. Assim, o conjunto de atividades cujas execuções convergem para a manutenção de um sistema administrativo dotado de autoridade, corresponde ao que denomina-se burocratização. A partir do autor, o burocrata pode ser entendido como aquele que executa serviços seguindo regras e obedecendo hierarquias numa conduta fiel ao que lhe é superior.

À medida que novas atividades são acrescidas ao cotidiano dos agentes, ajustando-os às necessidades de um sistema de controle e não às realidades com as quais trabalham, ocorre a burocratização da função (LOTTA, 2010) o que, de acordo com algumas falas, tem interferido negativamente no fortalecimento das relações bem como no trabalho mais próximo ao cotidiano da população (VASCONCELOS, 2017).

As atribuições conferidas aos Agentes Comunitários de Saúde foram, por algum tempo, resultado de negociações locais que consideravam as realidades do local (SILVA E DALMASO, 2002). Os documentos elaborados apresentam as linhas de ação dos Agentes Comunitários de Saúde de forma sumária, possibilitando uma ideia geral sobre seu perfil ocupacional, isto é, sobre uma organização formal das atividades típicas de um grupo profissional (NOGUEIRA et al., 2000). $O$ documento mais recente a este respeito é a Lei 13.595 que aponta para a Educação

\footnotetext{
${ }^{2}$ E-SUS é o sistema/estratégia de organização de registro e gerenciamento de informações da saúde da Atenção Básica.
} 
Popular em saúde cujos referenciais devem ser orientadores das ações (BRASIL, 2018). Contudo, a falta de uma especificação mais detalhada das atribuições, justificada pelas diferentes configurações sociais das diferentes localidades, dá abertura às entidades governamentais para agregar funções de acordo com as necessidades locais, mesmo que não correspondam ao que se espera da categoria, como no caso do município em questão.

De acordo com Vasconcelos (1987) questões como as expostas pelos Agentes constituem limites cuja superação é possível através do desenvolvimento de atividades, como realização de palestras, por exemplo, e outras atividades coletivas. Todavia, é preciso reconhecer que determinadas deliberações nem sempre estão ao alcance dos sujeitos em questão, de modo que esta superação depende também, da compreensão de outros atores sociais.

\section{CONCLUSÃO}

Os Agentes Comunitários de Saúde são trabalhadores que atuam na Atenção Primária à Saúde e têm um papel fundamental para o funcionamento do Sistema Único de Saúde. Em todo país, mais de 280 mil Agentes atuam diariamente, atendendo à população na medida que constroem uma ponte entre esta e os serviços de saúde.

As ações de promoção da saúde e prevenção de doenças são orientadoras das atividades da categoria, devendo ser desenvolvidas a partir de atividades de caráter individual e coletivo. A partir das necessidades locais outras atribuições podem ser agregadas.

No município de Mari-PB, observou-se que houve um período em que as atividades de caráter coletivo eram mais frequentes. Recentemente, tem sido dada prioridade à atividade de caráter mais individual. Os ACS se percebem como transmissores de informações, muitas vezes, para atender fins que não dizem respeito à função propriamente dita. o que tem contribuído para a geração de sobrecarga de atividades, em grande parte, burocráticas. Com isto, entendem que suas atividades profissionais têm ocasionado individualização da função, por exigir dedicação a atividades que nem sempre permitem a organização de momentos coletivos com os pares e com a comunidade. Mesmo com todas as dificuldades apresentadas 
e o surgimento de atividades nem sempre previstas na agenda, não houve indicação de que os ACS detenham alternativas ou capacidades de organização local para apresentar soluções para os problemas acumulados.

\section{AGRADECIMENTOS}

Agradecemos a CAPES/FAPESQ pelo apoio financeiro à pesquisa.

\section{REFERÊNCIAS}

BONSRSTEIN, Vera Joana. História e contexto de atuação dos agentes comunitários de saúde no Brasil. In: BORNSTEIN, Vera Joana (org.). Formação em educação popular para trabalhadores da saúde. Rio de Janeiro: EPSJV, 2017.

BRANDÃO, Carlos Rodrigues. O que é educação? São Paulo, Brasiliense, 1981.

BRASIL. Glossário temático: gestão do trabalho e da educação na saúde Ministério da Saúde. SecretariaExecutiva. Secretaria de Gestão do Trabalho e da Educação na Saúde. 2. ed. Brasília : Ministério da Saúde, 2012. (Série A. Normas e Manuais Técnicos). Disponível em: http://bvsms.saude.gov.br/bvs/publicacoes/glossario_tematico_gestao_trabalho_educacao_saude_2ed.pdf. Acesso em: 30 de julho de 2019.

BRASIL. Lei № 11.350 de 05 de outubro de 2006. Revoga a Lei no 10.507 de 10 de julho de 2002 e regulamenta o § 5을 do art. 198 da Constituição, dispõe sobre o aproveitamento de pessoal amparado pelo parágrafo único do art. $2^{\circ}$ da Emenda Constitucional $n^{\circ}$ 51, de 14 de fevereiro de 2006, e dá outras providências. Disponível em <http://www.planalto.gov.br/ccivil_03/_Ato2004-2006/2006/Lei/L11350.htm\#art21>. Acesso em: 05 de agosto de 2019

BRASIL. Lei № 13.595 de 05 de janeiro de 2018. Altera a Lei nº 11.350, de 5 de outubro de 2006, para dispor sobre a reformulação das atribuições, a jornada e as condições de trabalho, o grau de formação profissional, os cursos de formação técnica e continuada e a indenização de transporte dos profissionais Agentes Comunitários de Saúde e Agentes de Combate às Endemias. Disponível em <http://www.planalto.gov.br/ccivil_03/_Ato20152018/2018/Lei/L13595.htm>. Acesso em: 08 de agosto 2019.

BRASIL. 0 trabalho do Agente Comunitário de Saúde. Secretaria de Políticas de Saúde. Brasília: Ministério da Saúde, 2000.

BRASIL. Política Nacional de Atenção Básica. Brasília: Ministério da Saúde, 2012. Disponível em: <http://dab.saude.gov.br/portaldab/pnab.php>. Acesso em: 03 de agosto de 2019

BRASIL. Política Nacional de Atenção Básica. Brasília: Ministério da Saúde, 2017. Disponível em: $<$ http://bvsms.saude.gov.br/bvs/saudelegis/gm/2017/prt2436_22_09_2017.html> Acesso em: 04 de agosto de 2019 
BRASIL. Política Nacional de Atenção Básica. Brasília: Ministério da Saúde, 2006. Disponível em: <http://bvsms.saude.gov.br/bvs/publicacoes/politica_nacional_atencao_basica_2006.pdf>. Acesso em: 08 de agosto de 2019

BRASIL. Programa de Agentes Comunitários de Saúde. Brasília: Ministério da Saúde, 2001.

CARDOSO, L.; GALERA, S. A. F; VIEIRA, M. V. O cuidador e a sobrecarga do cuidado à saúde de pacientes egressos de internação psiquiátrica. Acta paul. enferm., v.25, n.4, pp.517-523, 2012. Disponível em: < https://www2.unifesp.br/acta/pdf/v25/n4/v25n4a6.pdf> Acesso em 09 de Agosto de 2019.

COULON, Alain. Etnometodologia. Petrópolis, Vozes, 1995.

GATTI, Bernadete Angelina. Grupo Focal na pesquisa em ciências sociais e humanas. Brasília. Cyber Livro, 2005

LOTTA, Gabriela Spanghero. Implementação de Políticas Públicas: o impacto dos fatores relacionais e organizacionais sobre a atuação dos Burocratas de Nível de Rua no Programa Saúde da Família. 2010,295 f. Tese (Doutorado em Ciência Política) Universidade de São Paulo. São Paulo. Disponível em: < http://www.teses.usp.br/teses/disponiveis/8/8131/tde-20102010-120342/pt-br.php> Acesso em 12 de Agosto de 2019.

MAMEDE, Marcia Mendes. Atendimento integrado à saúde e desenvolvimento da criança: módulo II: roteiro de visita domiciliar. Brasília, Ministério da Saúde, 1995.

MARCONI, Marina de Andrade; LAKATOS, Eva Maria. Fundamentos de Metodologia científica. São Paulo: Atlas, 2003. Disponível em: < https://docente.ifrn.edu.br/olivianeta/disciplinas/copy_of_historia-i/historia-ii/chinae-india> Acesso em 12 de Agosto de 2019.

MINAYO, Maria Cecília de Souza et al. Programa Agentes de Saúde do Ceará. Fortaleza: Fundo das Nações Unidas para a Infância (UNICEF), 1990.

MINAYO, Maria Cecília de Souza. o desafio do conhecimento: pesquisa qualitativa em saúde. 10. Ed. São Paulo, Hucitec, 2007.

NESPOLI, Grasiele. Da Educação sanitária à educação popular em saúde. In: BORNSTEIN, Vera Joana (org.). Formação em educação popular para trabalhadores da saúde. Rio de Janeiro: EPSJV, 2017. NOGUEIRA, R. P.; SILVA, F B. da; RAMOS, Z. V. O. A vinculação institucional de um trabalhador sui generis o Agente Comunitário de saúde. Brasília, Ministério do Planejamento, 2000.

SILVA, J. A. da; DALMASO, A. S. W. Agente Comunitário de saúde: o ser, o saber, o fazer. Rio de Janeiro: Editora FIOCRUZ, 2002.

VASCONCELOS, E. M. Educação Popular nos serviços de saúde. São Paulo. Hucitec, 1989.

VASCONCELOS, E. M. Redefinindo as práticas de saúde a partir da educação popular nos serviços de saúde. In: VASCONCELOS, E. M; PRADO, E. V. (Orgs). A saúde nas palavras e nos gestos: reflexões da rede de educação popular em saúde. São Paulo: Hucitec, 2017.

\section{$(\mathrm{cc}) \mathrm{Br}$}

Este trabalho está licenciado com uma Licença Creative Commons - Atribuição 4.0 Internacional. 